\title{
The role of UV photolysis and molecular transport in the generation of reactive species in a tissue model with a cold atmospheric pressure plasma jet
}

Bhagirath Ghimire, ${ }^{1}$ Endre J. Szili, ${ }^{2}$ Pradeep Lamichhane, ${ }^{1}$ Robert D. Short, ${ }^{2,3}$ Jun Sup Lim, ${ }^{1}$ Pankaj Attri, ${ }^{4}$ Kai Masur, ${ }^{5}$ Klaus-Dieter Weltmann, ${ }^{5}$ Sung-Ha Hong, ${ }^{2}$ and Eun $\mathrm{Ha} \mathrm{Choi}^{1, \mathrm{a})}$

${ }^{1)}$ Department of Electrical and Biological Physics, Plasma Bioscience Research Center, Kwangwoon University, Seoul 01897, Republic of Korea

${ }^{2)}$ Future Industries Institute, University of South Australia, Adelaide, SA 5095, Australia

${ }^{3)}$ Materials Science Institute and Department of Chemistry, The University of Lancaster, City of Lancaster LA1 $4 Y W, U K$

4) Research group PLASMANT, Department of Chemistry, University of Antwerp, BE-2610, Wilrijk-Antwerp, Belgium

${ }^{5)}$ INP Greifswald e.V., Felix-Hausdorff-Str. 2, 17489 Greifswald, Germany

(Dated: 6 February 2019)

Cold atmospheric plasma jets (plasma) operated into ambient air provide a rich source of reactive oxygen and nitrogen species (RONS), which are known to influence biological processes important in disease. In the plasma treatment of diseased tissue such as subcutaneous cancer tumors, plasma RONS need to first traverse an interface between the plasma-skin surface and second be transported to millimeter depths in order to reach the deep-seated diseased cells. However, the mechanisms in the plasma generation of RONS within soft tissues is not understood. In this study, we model the plasma jet delivery of RONS into a tissue model target and we delineate two processes: through target delivery of RONS generated (primarily) in the plasma jet and in situ RONS generation by UV photolysis within the target. We demonstrate that UV photolysis promotes the rapid generation of RONS in the tissue target's surface after which, the RONS are transported to millimeter depths via a slower molecular process. Our results imply that the flux of UV photons from plasma jets are important in delivering RONS through seemingly impenetrable barriers such as skin. The findings not only have implications in treatments of living tissues but also in the functionalization of soft hydrated biomaterials such as hydrogels and extracellular matrix derived tissue scaffolds.

The past two decades have seen the emergence of a new research field called "Plasma Medicine". The principle of Plasma Medicine involves the direct application of electrical, non-thermal, atmospheric plasma (herein referred to as "plasma") to living tissues for the treatment of disease. ${ }^{1-6}$ Encouraging outcomes from initial clinical trials in chronic wounds, cancers and dermatological indications, have fuelled significant worldwide optimism that plasma technologies could provide the basis for a range of major "breakthrough" medical therapies..$^{7-13}$

When operated into air, plasma generates a rich source of reactive oxygen and nitrogen species (RONS) through interaction of electrons, ions and excited state species with ambient gases. ${ }^{14-16} \mathrm{~A}$ plasma jet can entrain these RONS carrying them into the biological target. Further, the VUV/UV component of plasma can potentially create RONS directly within the target. ${ }^{17-19}$ Historically, RONS have been thought to be detrimental to human health, implicated in disease and the deterioration of physiological function with age. ${ }^{20}$ But this view has been revised as awareness has grown of the necessity of RONS for the maintenance of good health. ${ }^{21}$ RONS participate in a plethora of cellular signalling pathways, aid in wound healing and help the body fight against infectious diseases and cancers. ${ }^{15,22-27}$

During plasma treatment of diseased tissue, RONS need to traverse major barriers within the

\footnotetext{
a)Electronic mail: ehchoi@kw.ac.kr
} 
physiological environment, including the tissue fluid, tissue and the extracellular matrix, before finally reaching the target cell. ${ }^{28}$ Any explanation of the mode-of-action of plasma has to consider how the multitude of different RONS traverse the major barriers in tissue. This is very different to $2 \mathrm{D}$ in vitro culture where RONS are delivered into small volumes (typically a few hundred microliters) of media covering cells. As a starting point, experiments were developed to study the plasma delivery of RONS into agarose and gelatin, which were used as surrogates of tissue. ${ }^{29-35}$ These studies show that plasma delivers (more stable) RONS to millimeter depths into tissue models, potentially assisted by strong electric fields sustaining the plasma discharge ${ }^{29,35-38}$ and at concentrations exceeding hundreds of micromoles, which would (most likely) induce significant cellular responses. Recently, it was shown that plasma jets deliver RONS through millimeter-thick (real) biological tissue both in vitro (pig muscle) ${ }^{39}$ and in vivo (cancer tumour embedded underneath mouse skin). ${ }^{40}$ In addition, UV photons from the plasma source could rapidly generate the ${ }^{\bullet} \mathrm{OH}$ in situ to millimetre depths in water through UV photolysis. ${ }^{41,42}$ RONS are likely to be delivered through tissue by a combination of the above processes. It is imperative to understand how these processes influence RONS delivery.

In this study, we compare the roles of UV photolysis versus plasma jet delivery in the plasma

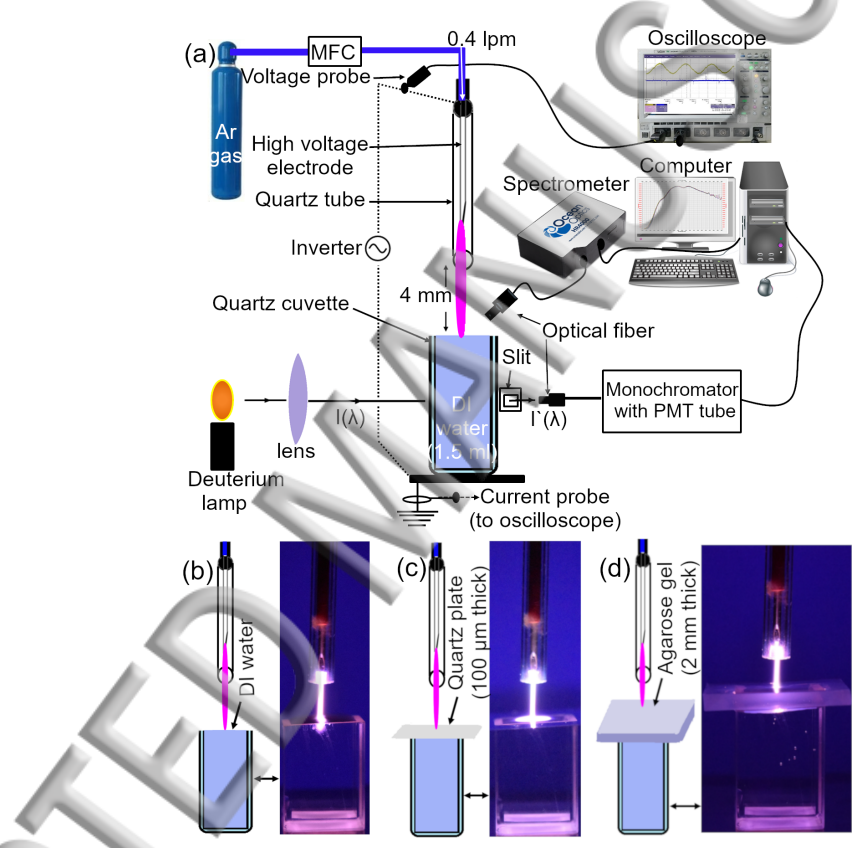

FIG. 1: (a) Experimental set-up to perform in situ measurements of RONS delivery into DI water during argon plasma jet exposure, and to measure in tandem the electrical and optical properties of the plasma jet. Schematics and photographs of the experimental set-ups are shown below to investigate RONS delivery from

(b) direct plasma exposure, (c) through quartz to assess UV photolysis and (d) through agarose to assess molecular transport. The set-ups in (b-d) were used for UV-vis spectroscopy and for the KI-starch gel jet generation of RONS in agarose, which is used as a perimental setup is shown in Fig. 1. An argon plasma jet was aimed at a quartz cuvette filled with deionized (DI) water. The water served as a reservoir to collect the plasma-generated molecules, which were subsequently detected by UV-vis spectroscopy. Alternatively, the cuvette was filled with $0.3 \%$ agarose containing an evenly dispersed mixture of $0.3 \%$ potassium iodide (KI) and 0.5 $\%$ starch (KI-starch gel), which enabled us to directly visualise RONS (without spectroscopy). The distance from the top of the water surface or KI-starch gel (the respective media in which plasmagenerated molecules were monitored) to the nozzle of the quartz tube of the plasma jet assembly was fixed at $4 \mathrm{~mm}$. At this distance, the plume from the plasma jet always contacted the surface of the target. Agarose was used as a simple barrier, similar to that encountered during plasma jet treatment of any biological tissue. Agarose is ideal for this study because it is a widely adopted tissue model for biomedical research. ${ }^{43-46}$ The experiment was designed to enable the analysis of RONS delivery from direct plasma exposure of DI water [Fig. 1(b)], and from indirect plasma exposure through quartz to assess UV photolysis [Fig. 1 (c)] and through agarose to assess passive transport 

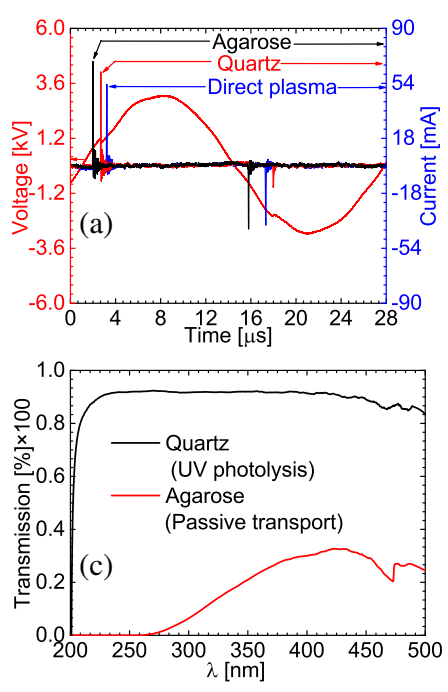
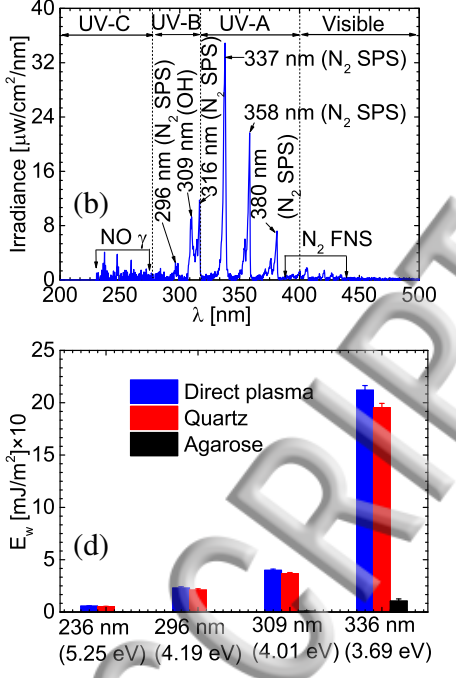

FIG. 2: (a) Electrical characteristics of the argon plasma jet (voltage and current waveforms) in contact with the DI water [Fig. 1(b)], quartz [Fig. 1(c)] and agarose [Fig. 1(d)]. (b) OES of the argon plasma jet operated into ambient air showing emissions for the visible, UV-A, UV-B and UV-C wavelength range. (c) Percentage transmittance for the quartz plate (UV photolysis) and agarose tissue model (passive transport). (d) Photon energy density delivered to the surface of the DI water $\left(E_{w}\right)$ for water directly exposed to the plasma jet and indirectly through the quartz or agarose.

[Fig. 1(d)].

The argon plasma jet has been described in detail elsewhere. ${ }^{47}$ Plasma was generated at a constant argon flow rate of 0.4 liters per minute $(\mathrm{lpm})$ and powered with a custom-built inverter operated at $5.2 \mathrm{~V}$ with of frequency of $35 \mathrm{kHz}$. The discharge current-voltage waveforms recorded for the plasma jet in contact with the three targets [Fig. 1(b), 1(c) \& 1(d)] are shown in Fig. 2(a). For all targets, every positive and negative half cycles of the discharge are characterized by single current peaks, respectively. However, the peak magnitudes of the current peaks and their positions did vary. These differences were attributed to the reduction in breakdown voltage caused by the introduction of the target materials of different thickness (see supplementary information S1).

Measurements of the spectral composition of the argon plasma jet in contact with the surface of the DI water (Fig. 1(a)) were made by optical emission spectroscopy (OES) and the results are shown in Fig. 2(b) (see supplementary information S1 for other conditions). Emissions from the nitrogen second positive system ( $\mathrm{N}_{2} \mathrm{SPS}$ ) at $316 \mathrm{~nm}, 336 \mathrm{~nm}, 357 \mathrm{~nm}$ and $380 \mathrm{~nm}$ and nitrogen first negative system $\left(\mathrm{N}_{2}\right.$ FNS - 390 to $\left.440 \mathrm{~nm}\right)$ dominate the UV-A region $(315-400 \mathrm{~nm})$. These excited nitrogen molecules are produced upon collision of the electrons/argon metastables with ambient air molecules. ${ }^{41,42,47}$ Utilizing the 0-2 vibrational band of $\mathrm{N}_{2}$ SPS (peak wavelength at $380.4 \mathrm{~nm}$ ), we determined the gas temperature close to the surface of the DI water to be $\approx 350 \mathrm{~K}$. The emissions in the UV-B (280-315 $\mathrm{nm}$ ) region also includes the $\mathrm{N}_{2}$ SPS at $296 \mathrm{~nm}$ and $311 \mathrm{~nm}$ in addition to the - $\mathrm{OH}$ at $309 \mathrm{~nm}$ produced through dissociation of water molecules in the surrounding humid air. ${ }^{48}$ The UV-C (200-280 nm) region consists of lower intensity emissions from the $\mathrm{NO}^{\gamma}$ band (236 $\mathrm{nm}$, $247 \mathrm{~nm}, 258 \mathrm{~nm}, 283 \mathrm{~nm}$, etc). Photons detected in the plasma jet have energies in the range of $3.27-5.25 \mathrm{eV}(380 \mathrm{~nm}-236 \mathrm{~nm})$, which are higher than the energy required for the dissociation of water molecules through $\mathrm{UV}$ photolysis through reactions: ${ }^{42}$ (i) $\mathrm{UV}+\mathrm{H}_{2} \mathrm{O} \rightarrow \mathrm{H}_{2} \mathrm{O}^{*}$; (ii) $\mathrm{UV}+\mathrm{H}_{2} \mathrm{O}^{*}$ $\rightarrow \mathrm{H}^{+}+\mathrm{OH}^{-}$; and (iii) $\mathrm{OH}^{-} \rightarrow \cdot \mathrm{OH}+\mathrm{e}^{-}$.

Fig. 2(c) shows the percentage of transmittance through the quartz plate and agarose, respectively. Transmittance through the quartz plate (at over $80 \%$ ) was much higher than for agarose, which absorbed most of the photon energy. The photon energy density (at various wavelengths) delivered per unit area to the water surface $\left(E_{w}\right)$ was measured for the quartz plate experimental configuration [Fig. 1(c)] (The $E_{w}$ could not be directly measured for direct plasma and through agarose exposures due to changes in the optical property of the plasma (when in close proximity to the metal housing of the optical fiber) and low optical emission signal through agarose, respectively), according to equation (1) where the absolute irradiance $(I)$ for a particular wavelength $(\lambda)$ was calculated using 
a deuterium halogen lamp of known output energy $(C(\lambda)): 49$

$$
I(\lambda)=\frac{S(\lambda)-D(\lambda)}{T \times A \times d \lambda} \times C(\lambda)
$$

Here, $S(\lambda), D(\lambda), T, A$, and $d \lambda$ represent intensity of sample spectrum, intensity of background spectrum acquired in the dark, integration time of the spectrometer, collection area $\left(0.12 \mathrm{~cm}^{2}\right)$ and wavelength spread, respectively. $I(\lambda)$ and $C(\lambda)$ have the units of $\mu W / \mathrm{cm}^{2} / \mathrm{mm}$ and $\mu J /$ count, respectively. The $E_{w}$ (converted to $m J / \mathrm{m}^{2}$ ) was obtained by multiplying $I(\lambda)$ with the integration time of the spectrometer (set to $600 \mathrm{~ms}$ ) and wavelength spread (1 nm). Additional details of the measurement and calculation of the $E_{w}$ for the water, quartz and agarose targets are provided in the supplementary information S2. The $E_{w}$ measured for major emissions of UV-C (236 $\left.\mathrm{nm}\right)$, UV-B $(296 \mathrm{~nm}, 309 \mathrm{~nm})$ and UV-A $(336 \mathrm{~nm})$ for direct plasma and for plasma exposures through quartz and agarose are shown in Fig. 2(d). Here it can be seen that the photon energy density was high enough to facilitate UV photolysis of water through the quartz plate, but was significantly attenuated by the agarose.

The RONS concentrations within DI water for direct plasma exposure and for plasma exposure through the quartz plate and agarose targets were determined by measuring the UV-vis absorbance spectra between 220-340 $\mathrm{nm}$, according to an established procedure. ${ }^{33}$ Measurements were carried out at a $3 \mathrm{~mm}$ position below the top of the cuvette. Fig. 3 shows the changes in absorbance as a function of plasma jet exposure time. The plasma jet was switched on for the first 6 minutes, after which the plasma and gas flow were switched off; UV-vis absorbance spectra were recorded for up to 66 minutes. For water directly exposed to the plasma jet, it can be seen that there was an immediate and monotonic increase in the absorbance when the plasma was on. After switching off the plasma and gas flow at $\mathrm{t}=6$ minutes, the absorbance remained constant as no further RONS were generated. In this case, RONS will arise from a multitude of processes; those contributing to more highly-reactive RONS (e.g. the ${ }^{\bullet} \mathrm{OH}$ ) and more stable molecules. These RONS are generated both in the plasma (and carried to the target with the plasma jet effluent) and directly within the target itself (through UV photolysis). For treatment through the quartz plate, the absorbance once again increased immediately and monotonically; but at $\mathrm{t}=6$ minutes, the total absorbance was only $4 \%$ of that achieved with direct plasma exposure (indicating much lower RONS concentrations in the DI water). In this configuration, RONS created in the plasma-air effluent are not delivered into the DI water (the quartz blocks delivery) and we only measure those RONS created in situ by UV photolysis of the DI water (most likely the ${ }^{\bullet} \mathrm{OH}$ ). When the plasma and gas were switched off, the absorbance decreased to zero by $\mathrm{t}=12$ minutes. The ${ }^{\bullet} \mathrm{OH}$ can recombine with a neighboring - $\mathrm{OH}$ forming hydrogen peroxide $\left(\mathrm{H}_{2} \mathrm{O}_{2}\right)$, which is stable in DI water. ${ }^{42,50}$ Although $\mathrm{H}_{2} \mathrm{O}_{2}$ also contributes to the UV absorbance, its UV absorption cross-section is smaller than the ${ }^{\bullet} \mathrm{OH}$, which resulted in the diminishing absorbance signal. ${ }^{51-53}$ For plasma exposure through agarose, there was no change in the UV-vis absorbance whilst the plasma was ignited, i.e. for up to $t=6$ minutes. However, during the period after the plasma was switched off (and no longer generating RONS), the $\mathrm{UV}$-vis absorbance began to increase at $\mathrm{t}=9$ minutes and continued to increase for the remainder of the measurement period up to $t=66$ minutes, at which point the absorbance had easily exceeded that obtained by UV photolysis. This suggests that the RONS, initially created in the agarose by the plasma jet, migrated through the tissue model and subsequently into the DI water by slower molecular transport (as opposed to faster UV photolysis). ${ }^{31}$

In the next experiments, a KI-starch gel (replacing DI water) was used to visualise both RONS delivery and in situ generation from the plasma. The principle is based upon RONS oxidising iodide ions with the starch to produce a stable, brown coloured complex (See references [34, 54, 55] and supplementary information S3 for further details). The gel was dispensed inside a cuvette and the experiments were repeated to assess RONS delivery (into the KI starch gel) from direct plasma exposure, and through the quartz and agarose targets. Fig. 4 shows the cross-sections of the plasmaexposed KI-starch gel. For direct plasma exposure, a "V-shaped" brown pattern is seen to a depth of $6 \mathrm{~mm}$ in the gel, attributed to the combined effect from plasma jet delivery and in situ generation of RONS. At $\mathrm{t}=36$ minutes, the brown area is wider and deeper at $8 \mathrm{~mm}$. At $\mathrm{t}=66$ minutes, the brown area has filled the width of the cuvette and penetrated deeper to $11 \mathrm{~mm}$. For plasma exposure through quartz, a lighter brown area (compared to direct plasma exposure) has penetrated $1 \mathrm{~mm}$ subsurface immediately after plasma exposure $(t=6$ minutes $)$ and it faded over time. This result indicates that UV photolysis is limited to the uppermost surface. For plasma exposure through 

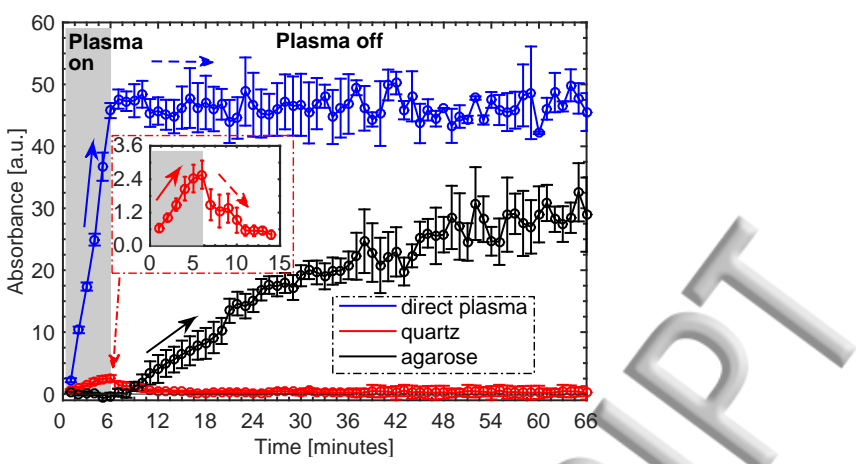

FIG. 3: Time-dependent changes in UV absorbance during and after argon plasma jet exposure of DI water directly exposed to the plasma jet, and indirectly through quartz to assess UV photolysis or through agarose to assess molecular transport. The shaded region indicates the time when the plasma was on (up to $t=6$ minutes). At $t=6$ minutes, plasma and gas flow were switched off and absorbance measurements were taken up to $\mathrm{t}=66$ minutes. Positive and negative slopes are marked with solid and dashed arrows, respectively.

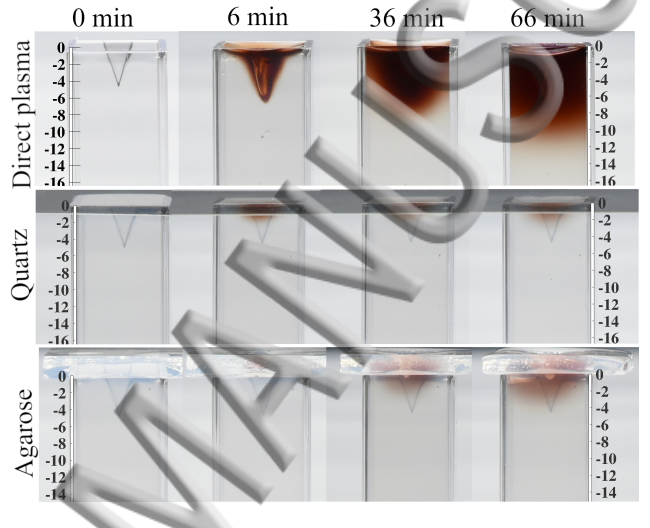

FIG. 4: Cross-section view of the KI-starch gel after 6 minutes of direct argon plasma jet exposure (Row 1), and after indirect exposure through quartz to assess UV photolysis (Row 2) and through agarose to assess passive transport (Row 3). Column 1: Untreated KI-starch gel $(\mathrm{t}=0$ minutes); Column 2: Immediately after plasma exposure $(\mathrm{t}=6$ minutes); Column 3: 30 minutes after plasma exposure $(\mathrm{t}=36$ minutes $)$; Column 4 : 60 minutes after plasma exposure $(\mathrm{t}=66$ minutes $)$. Scale bar: 1 division $=2 \mathrm{~mm}$.

agarose, a light brown colored region seen immediately after treatment ( $\mathrm{t}=6$ minutes) is seen to penetrate to a depth of $2 \mathrm{~mm}$ in the KI-starch gel after $\mathrm{t}=36$ minutes. At $\mathrm{t}=66$ minutes, the coloured area filled the width of the cuvette to a depth of $4 \mathrm{~mm}$.

From the KI-starch gel experiments, it was seen that the brown coloured region (i.e. region indicating RONS) over time, increased in intensity, expanded and penetrated deeper for direct and through agarose plasma exposures (whereas for plasma exposure through quartz, the colour was limited to the surface of the gel). In direct plasma exposure, there are both shorter-lived RONS such as the ${ }^{\circ} \mathrm{OH}$ and longer-lived, less-reactive molecules such as $\mathrm{H}_{2} \mathrm{O}_{2}, \mathrm{NO}_{2}^{-}$and $\mathrm{NO}_{3}^{-}$. 55,56 These less-reactive molecules have lower oxidative potentials; e.g. the oxidative potential of $\mathrm{H}_{2} \mathrm{O}_{2}$ is 1.7 $V$ compared to $2.8 \mathrm{~V}$ for the ${ }^{\bullet} \mathrm{OH},{ }^{54}$ but the less-reactive molecules contribute to the pro-longed, slower oxidation of the iodide ions. In the case of plasma exposure through agarose, the highlyreactive RONS were rapidly extinguished near the surface of the agarose tissue model, but the less-reactive molecules (e.g., $\mathrm{H}_{2} \mathrm{O}_{2}, \mathrm{NO}_{2}^{-}$and $\mathrm{NO}_{3}^{-}$) were slowly transported through the tissue model into the KI-starch gel underneath, where they oxidised the iodide ions.

We tested if $1 \mathrm{mM}$ concentrations of $\mathrm{H}_{2} \mathrm{O}_{2}, \mathrm{NaNO}_{2}$ and $\mathrm{HNO}_{3}$ (donors of $\mathrm{NO}_{2}^{-}$and $\mathrm{NO}_{3}^{-}$, respectively), can oxidise the KI-starch gel (Fig. 5). All three molecules oxidised the KI-starch gel. But their oxidation efficiency and penetration depth varied. $\mathrm{H}_{2} \mathrm{O}_{2}$ was the most efficient at oxidising the KI-starch gel and $\mathrm{NaNO}_{2}$ was the weakest. However, $\mathrm{NaNO}_{2}$ penetrated deeper than the other molecules. In combination, $\mathrm{NaNO}_{2}+\mathrm{HNO}_{3}$ or $\mathrm{H}_{2} \mathrm{O}_{2}+\mathrm{NaNO}_{2}+\mathrm{HNO}_{3}$ were more efficient at oxidising the KI-starch gel compared to any of the individual molecules. This observation was explained by the decrease in the $\mathrm{pH}$ of the DI water (main component in the gels) after addition of $\mathrm{HNO}_{3}$ and after plasma jet exposure (Supplementary information $\mathrm{S} 4$ ). The lowering of the $\mathrm{pH}$ by 


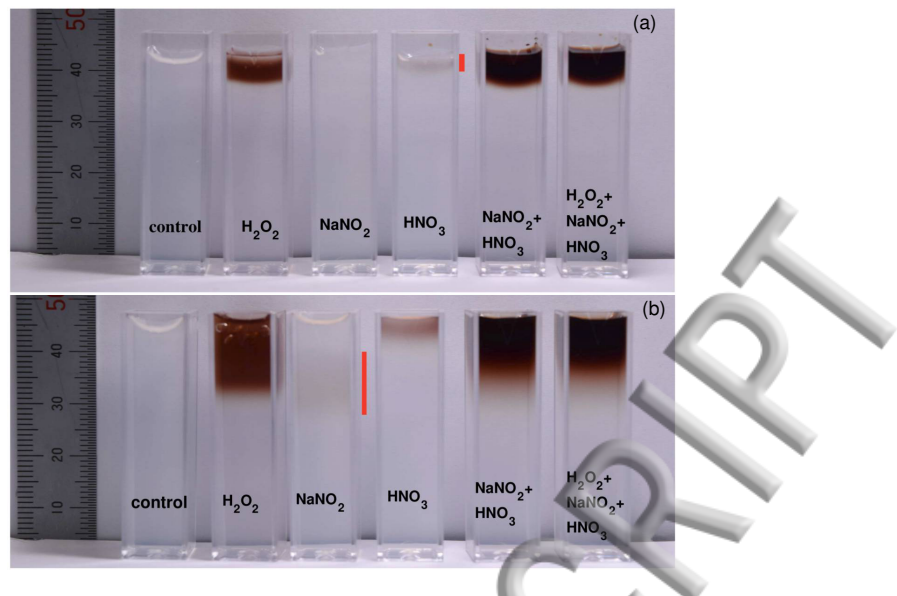

FIG. 5: Photographs of the KI-starch gel after $150 \mu$ volumes of $1 \mathrm{mM} \mathrm{H} \mathrm{H}_{2}, \mathrm{NaNO}_{2}$ and $\mathrm{HNO}_{3}$ or mixtures of these were dispensed on top of the gel and incubated for (a) 25 and (b) 60 minutes. The vertical red line on the right of the cuvette indicates the brown region in the cuvette for $\mathrm{HNO}_{3}$ in (a) and in $\mathrm{NaNO}_{2}$

(b). Control is KI-starch gel only.

the plasma jet might facilitate peroxynitrite chemistry through the reaction : $\mathrm{NO}_{2}^{-}+\mathrm{H}_{2} \mathrm{O}_{2}+\mathrm{H}^{+}$ $\rightarrow \mathrm{ONOOH}+\mathrm{H}_{2} \mathrm{O} .{ }^{57}$ Since, peroxynitrite (derivative of peroxynitrous acid, $\mathrm{ONOOH}$ ) is a potent oxidant, it would significantly enhance the oxidation of the KI-starch gel.

Our observations in Fig. 3 and Fig. 4 indicate that the effect of direct plasma is much stronger than UV photolysis alone during plasma treatment. However, with the caveat that we have not been able to measure photons in the VUV region [ $\operatorname{Ar}_{2}^{*}(126 \mathrm{~nm}), \operatorname{Ar}^{*}(106 \mathrm{~nm}, 107 \mathrm{~nm}), \mathrm{N}_{2}$ and $\mathrm{O}(130$ $\mathrm{nm})$, etc.] as these are blocked by the quartz plate. It is possible that the stronger effect in total UV absorbance as well as color changes of the KI-starch gel in the case where the plasma jet directly contacts the liquid surface could be attributed to the direct effect of UV/VUV exposure (which is eliminated with indirect plasma jet exposure through the quartz plate). ${ }^{18,19}$ In this case, these high energy photons would be adsorbed in the surface of any target, and $\bullet \mathrm{OH}$ generated would be initially highly localised to the surface: whilst stable RONS are transported deep into the tissue model target on a timescale of minutes. In real applications of plasmas in medicine, we cannot tailor the role of specific plasma components; all of the components (electrons, ions, UVs, metastables, electric fields, etc.) will act in synergy in the delivery of the active agents into tissue. It is paramount to understand how each plasma component facilitates the delivery of the active agents (e.g. RONS) into tissue. In order to progress this research, innovative plasma jets will need to be developed such as those designed to separate photons from reactive particles. ${ }^{58}$

The ability of plasma jets to generate reactive species deep within tissue opens significant opportunities for the development of medical plasma technologies for treatment of refractory indications such as chronic wounds and cancers. However, we still need to develop a much more detailed understanding of how to control the plasma delivery of RONS into tissue; and once delivered into tissue, a better understanding of their spatiotemporal concentrations (during and post plasma treatment). This knowledge should help inform the development of more targeted plasma-based therapies for achieving better medical outcomes. Our present study aimed to address (in part) this gap in our knowledge.

Supplementary Material: S1.Characteristics of the plasma jet contacting DI water, quartz plate and agarose; S2.Determination of the photon energy density delivered to the water surface $\left(E_{w}\right)$; S3.Oxidation of the KI-starch gel; and S4.pH of DI water after addition of $\mathrm{H}_{2} \mathrm{O}_{2}, \mathrm{NaNO}_{2}$ and $\mathrm{HNO}_{3}$ and after argon plasma jet exposure.

This work was supported by a National Research Foundation of Korea (NRF) grant NRF2016K1A4A3914113, and in part by Kwangwoon University, Korea. EJS, S-HH and RDS wish to thank the Australian Research Council for partially supporting this research through Discovery Project DP16010498 and UniSA through the Vice Chancellor Development Fund.

${ }^{1}$ A. Shashurin, M. Keidar, S. Bronnikov, R. A. Jurjus, M. A. Stepp, Appl. Phys. Lett. 93, 181501 (2008).

${ }^{2}$ M. Keidar, A. Shashurin, O. Volotskova, M. A. Stepp, P. Srinivasan, A. S., B. Trink, Phys. Plasmas 20, 057101 (2013). 
${ }^{3}$ S. Fathollah, S. Mirpour, P. Mansouri, A. R. Dehpour, M. Ghoranneviss, N. Rahimi, Z. S. Naraghi, R. Chalangari, and K. M. Chalangari, Sci Rep 6, 1 (2016).

${ }^{4}$ S. Kubinova, K. Zaviskova, L. Uherkova, V. Zablotskii, O. Churpita, O. Lunov, and A. Dejneka, Sci Rep 7, 1 (2017).

${ }^{5}$ S. Mirpour, S. Piroozmand, N. Soleimani, N. J. Faharani, H. Ghomi, H. F. Eskandari, A. M. Sharifi, S. Mirpour, M. Eftekhari, and M. Nikkhah, Sci Rep 6, 1 (2016).

${ }^{6}$ M. Keidar, D. Yan, I. I. Beilis, B. Trink, and J. H. Sherman, Trends in Biotechnology 36, 586 (2018).

${ }^{7}$ G. Isbary, G. Morfill, H. Schmidt, M. Georgi, K. Ramrath, J. Heinlin, S. Karrer, M. Landthaler, T, Shimizu, B. Steffes, W. Bunk, R. Monetti, J. Zimmerman, R. Pompl, W. Stolz, Br. J. Dermatol. 163, 78 (2010).

${ }^{8}$ H. R. Metelmann, C. Seebauer, V Miller, A. Fridman,G. Bauer, D. B. Graves, J.M. Pouvesle, R. Rutkowski, M. Schuster, S. Bekeschus et al, Clinical Plasma Medicine 2212 (2017).

${ }^{9}$ S. Emmert, F. Brehmer, H. Hanble, A. Helmke, N. Mertens, R. Ahmed, D. Simon, D. Wandke, W. M. -Friedrichs, G. Daschlein, M. P. Schon, W. Viol, Clinical Plasma Medicine 1, 24 (2013).

${ }^{10}$ J. Heinlin, J. L. Zimmermann, F. Zeman, W. Bunk, G. Isbary, M. Landthaler, T. Maisch, R. Monetti, G. Morfill, T. Shimizu, J. Steinbauer, W. Stolz, and S. Karrer, Wound Repair Regen. 21, 800 (2013).

${ }^{11}$ J. Heinlin, G. Isbary, W. Stolz, G. Morfill, M. Landthaler, T. Shimizu, B. Steffes, T. Nosenko, J. L. Zimmermann, and S. Karrer, J. Eur. Acad. Dermatol. Venereol. 25, 1 (2011).

${ }^{12}$ G. Isbary, J. Heinlin, T. shimizu, J. L. Zimmermann, G. Morfill, H.-U. Schmidt, R. Monetti, B. Steffes, W. Bunk, Y. Li, T. Klaempfl, S. Karrer, M. Landhaler, and W. Stolz, Br. J. Dermatol. 167, 404 (2012).

${ }^{13}$ G. Isbary. W. Stolz, T. Shimizu, R. Monetti, W. Bunk, H. -U. Schmidt, G. Eg. Morfill, T. G. Klampfl, B. Steffes, H. mi Thomas, J. Heinlin, S. Karrer, M. Landthaler, J. 1. Zimmermann, Clinical Plasma Medicine 1, 25 (2013).

${ }^{14}$ S. Kelly, and M. M. Turner, Plasma Sources Sci. Technol. 23, 065013 (2014).

${ }^{15}$ X. Lu, G.V. Naidis, M. Laroussi, S. Reuter, D.B. Graves, and K. Ostrikov, Phys. Rep. 630, 1 (2016).

${ }^{16}$ X. Lu, K. Ostrikov, Appl. Phys. Rev. 5, 031102 (2018).

${ }^{17}$ H. Jablonowski, R. Bussiahn, M. U. Hammer, K.-D. Weltmann, Th. von Woedtke, and S. Reuter, Phys. Plasmas 22, 122008 (2015).

${ }^{18}$ N. Y. Babaeva and M. J. Kushner, J. Phys. D: Appl. Phys. 46, 025401 (2013).

${ }^{19}$ W. Tian and M. J. Kushner, J. Phys. D: Appl. Phys. 47, 165201 (2014).

${ }^{20}$ D. Harman, Journal of Gerontology 11, 298 (1956).

${ }^{21} \mathrm{~B}$. Halliwell and J. Gutteridge, Free radicals in biology and medicine, 4 ed. (Oxford Univeristy Press, 2007).

${ }^{22}$ T. Finkel, The Journal of Cell Biology 194, 7 (2011).

${ }^{23}$ L. Rio, L. M. Sandalio, F. J. Corpas, J. M. Palma and J. B. Barrosol, Plant Physiol. 141, 330 (2006).

${ }^{24}$ H. J. Ahn, K. I. Kim, N. N. Hoan, C. H. Kim, E. Moon, K. S. Choi, S. S. Yang and J. -S. Lee, Plos One 9, 1 (2013).

${ }^{25}$ N. Kaushik, N Uddin, G. B. Sim, Y. J. Hong, K. Y. Baik, C. H. Kim, S. J. lee, N. Kaushik and E. H. Choi, Sci Rep 5, 1 (2015).

${ }^{26}$ S. J. Kim and T. H. Chung, Appl. Phys. Lett. 107, 063702 (2015).

${ }^{27}$ D.B.Graves, J. Phys. D: Appl. Phys. 45, 263001 (2012).

${ }^{28}$ E. J. Szili, S.-H. Hong, J.-S. Oh, N. Gaur, and R. D. Short, Trends Biotechnol. 0167 (2017).

${ }^{29}$ E. J. Szili, J. W. Bradley and R. D. Short, J. Phys. D: Appl. Phys. 47, 152002 (2014).

${ }^{30}$ E. J. Szili, J.S. Oh, S.H. Hong, A. Hatta, and R. D. Short, J. Phys. D: Appl. Phys. 48, 202001 (2015).

${ }^{31}$ J. S. Oh, E. J. Szili, N. Gaur, S. H Hong, H. Furuta, H. Kurita, A. Mizuno, A. Hatta, and R. D. Short, J. Phys. D: Appl. Phys. 49, 304005 (2016)

${ }^{32}$ J. S. Oh, E. J. Szili, S. Ito, S./H. Hong, N. Gaur, H. Furuta, R. D. Short, A. Hatta, Plasma Medicine 5, 125 (2015).

${ }^{33}$ J. -S. Oh, E. J. Szili, N. Gaur, S. -H. Hong, H. Furuta, R. D. Short, and A. Hatta, Journal of Photopolymer Science, Technology 28, 439 (2015).

${ }^{34}$ T. Kawasaki, A. Sato, S. Kusumegi, A. Kudo, T. Sakanoshita, T. Tsurumaru, G. Uchida, K. Koga and M. Shiratani, Appl. Phys.Express 9, 076502 (2016).

${ }^{35}$ T. He, D. liu, H. xu, Z. Liu, D. Xu, D. Li, Q. Li, M. Rong and M. G. Kong, J. Phys. D: Appl. Phys. 49, 205204 (2016).

${ }^{36}$ T. He, D. Liu, Z. Liu, Z. Liu, Q. Li, M. Rong, and M. G. Kong, Appl. Phys. Lett. 111, 203702 (2017).

${ }^{37}$ E. Robert, T. Darny, S. Dozias, S. Iseni, and J.M. Pouvesle, Phys. Plasmas 22, 122007 (2015).

${ }^{38}$ M. Yusupov, J. Van der Paal, E.C. Neyts, and A. Bogaerts, Biochimica et Biophysica Acta 1861, 839 (2017).

${ }^{39}$ J. Duan, X. Lu and G. He, Phys. Plasmas 24, 073506 (2017).

${ }^{40}$ E.J. Szili, J.-S. Oh, H. Fukuhara, R. Bhatia, N. Gaur, C.K. Nguyen, S.-H. Hong, S. Ito, K. Ogawa, C. Kawada, T. Shuin, M. Tsuda, M. Furihata, A. Kurabayashi, H. Furuta, M. Ito, K. Inoue, A. Hatta, R.D. Short, Plasma Sources Sci. Technol. 27, 014001 (2017).

${ }^{41}$ Y. H. Kim, Y. J. Hong, K.Y. Baik, G. C. Kwon, J. J. Choi, G. S. Cho, H. S. Uhm, D. Y. Kim, and E. H. Choi, Plasma Chem. Plasma Process. 34, 457 (2014).

${ }^{42}$ P. Attri, Y. H. Kim, D. H. Park, J. H. Park, Y. J. Hong, H. S. Uhm, K. N. Kim, A. Fridman, and E. H. Choi, Sci Rep 5, 9332 (2015).

${ }^{43}$ P. Hilderbrand, Surgical Endoscopy 21, 1745 (2007).

${ }^{44}$ D.J. Scott, W. N. Young, L. M. Watumull, G. Lindberg, J. B. Fleming, R. V. Rege, R. J. Brawn, and D. B. Jones, J. Gastrointest. Surg. 4, 620 (2000).

${ }^{45}$ G. D. Taylor and J. A. Cadeddu, Br. J. Urol. 97, 179 (2006).

${ }^{46}$ Z.-J. Chen, G. T. Gillies, W. C. Broaddus, S. S. Prabhu, H. Fillmore, R. M. Mitchell, F. D. Corwin, and P. P. Fatouros, J. Neurosurg. 101, 304 (2004).

${ }^{47}$ B. Ghimire, J. Sornsakdanuphap, Y. J. Hong, H. S. Uhm, K. D. Weltmann and E. H. Choi, Phys. Plasmas 24, 073502 (2017).

${ }^{48}$ N. Srivastava, and C. Wang, J. Appl. Phys. 110, 053304 (2011).

${ }^{49}$ Ocean Optics Inc., "https://oceanoptics.com/measurementtechnique/irradiance/," accessed 2018. 
${ }^{50}$ H. S. Uhm, Phys. Plasmas 22, 123506 (2015).

${ }^{51}$ G.L. Vaghjiani, and A.R. Ravishankara, J. Geophys. Res. 94, 3487 (1989).

${ }^{52}$ R. Atkinson, D.L. Baulch, R.A. Cox, J.N. Crowley, R.F. Hampson, R.G. Hynes, M.E. Jenkin, M.J. Rossi, and J. Troe, Atmos. Chem. Phys. 4, 1461 (2004).

${ }^{53}$ C.-L. Lin, N.K. Rohatgi, and W.B. DeMore, Geophys. Res. Lett. 5, 113 (1978).

${ }^{54}$ A. Nakajima, G. Uchida, T. Kawasaki, K. Koga, T. Sarinont, T, Amano, K. Takenaka, M. Shiratani, and Y. Setsuhara, J. Appl. Phys. 118, 043301 (2015).

${ }^{55}$ G. Uchida, A. Nakajima, T. Ito, K. Takenaka, T. Kawasaki, K. Koga, M. Shiratani, and Y. Setsuhara, J. Appl. Phys. 120, 203302 (2016).

${ }^{56}$ X. Lu, G.V. Naidis, M. Laroussi, and K. Ostrikov, Phys. Rep. 540, 1 (2014).

${ }^{57}$ P. Lukes, E. Dolezalova, I. Sisrova, and M. Clupek, Plasma Sources Sci. Technol. 23, 015019 (2014).

${ }^{58}$ S. Schneider, F. Jarzina, J. -W. Lackmann, J. Golda, V. Layes, V. S. Gathen, J. E. Bandow, and J. Benedikt, J. Phys. D: Appl.Phys. 48, 444001 (2015). 


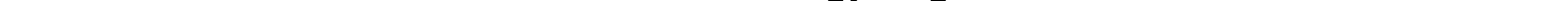




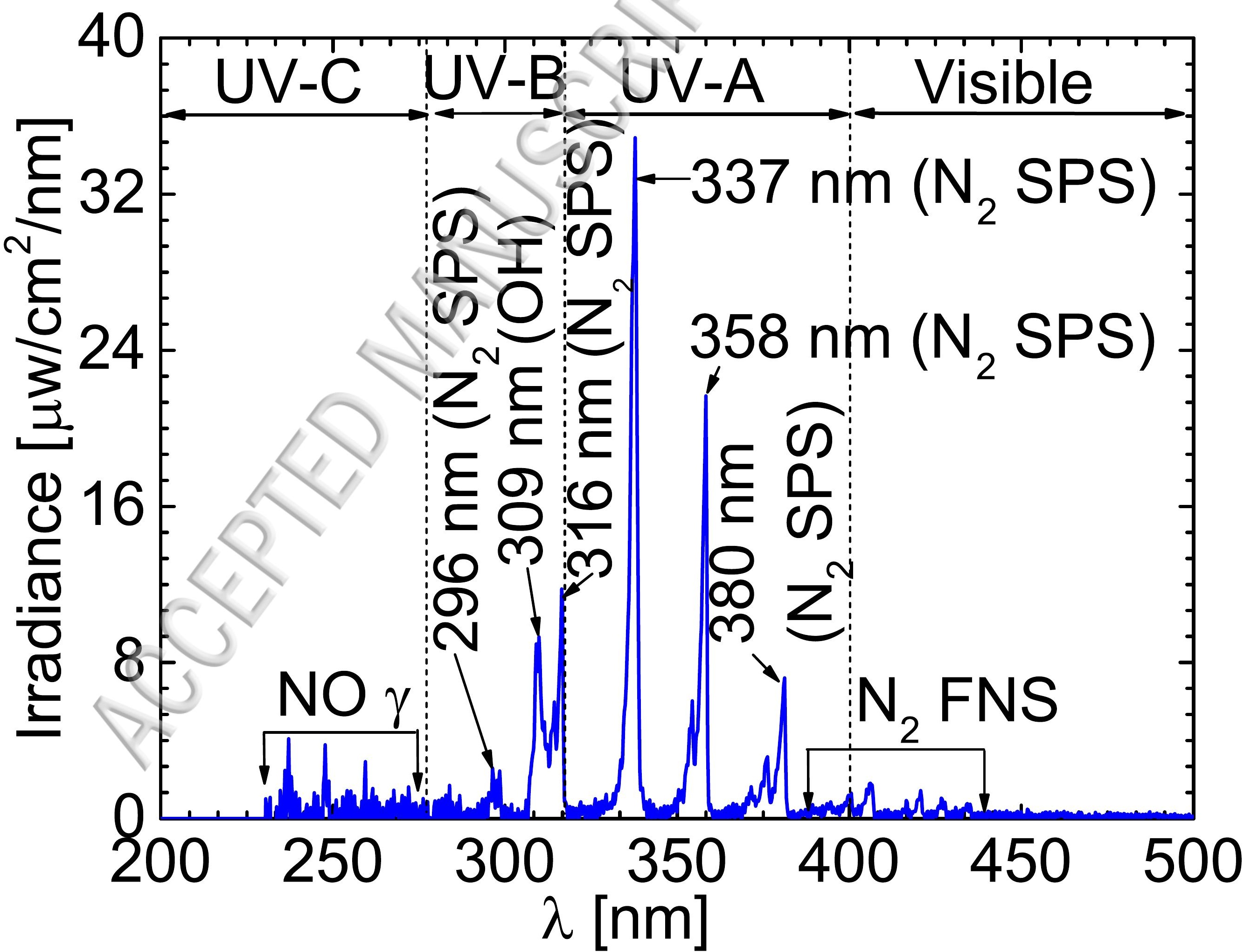




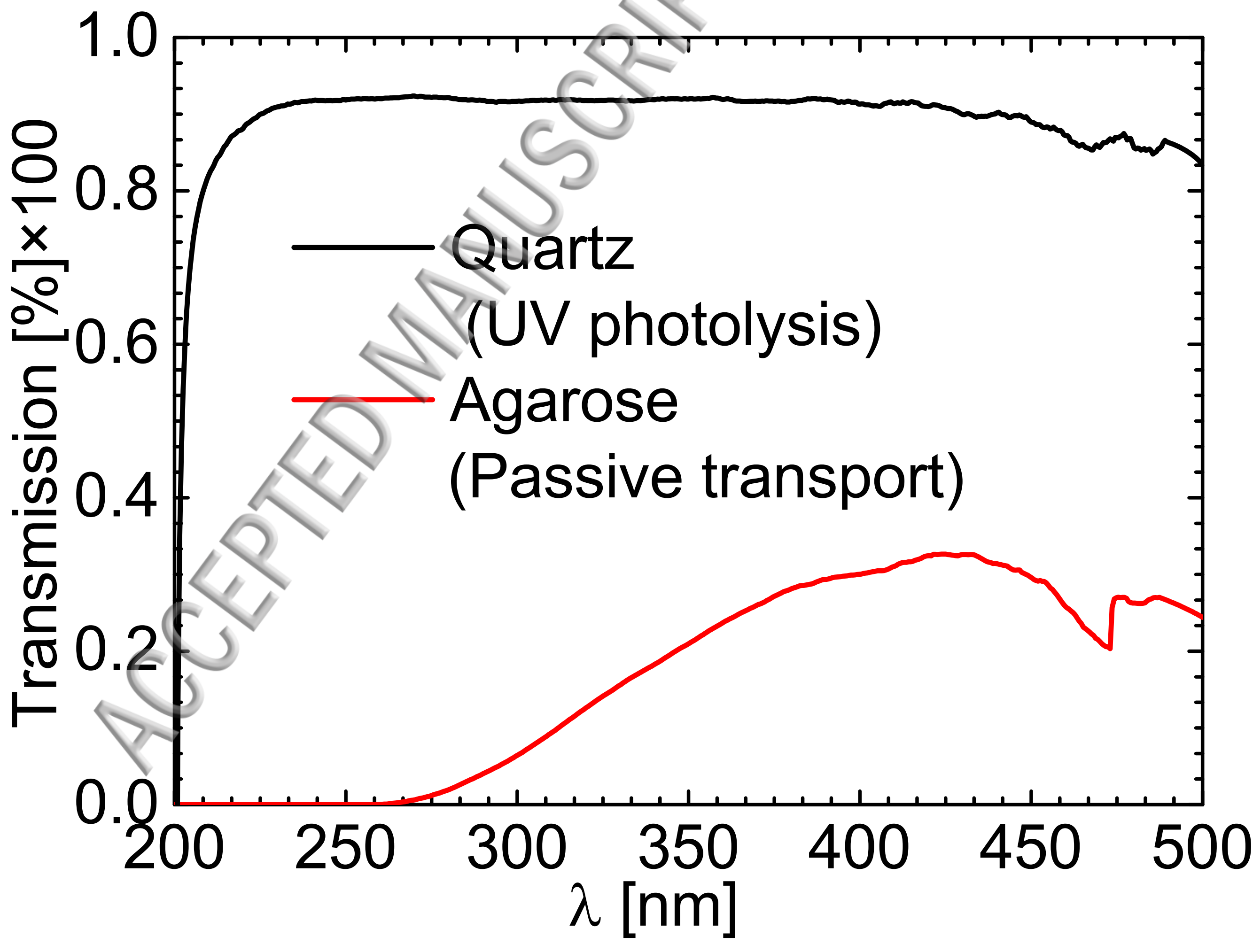




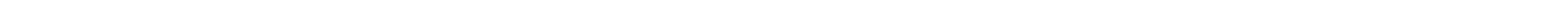




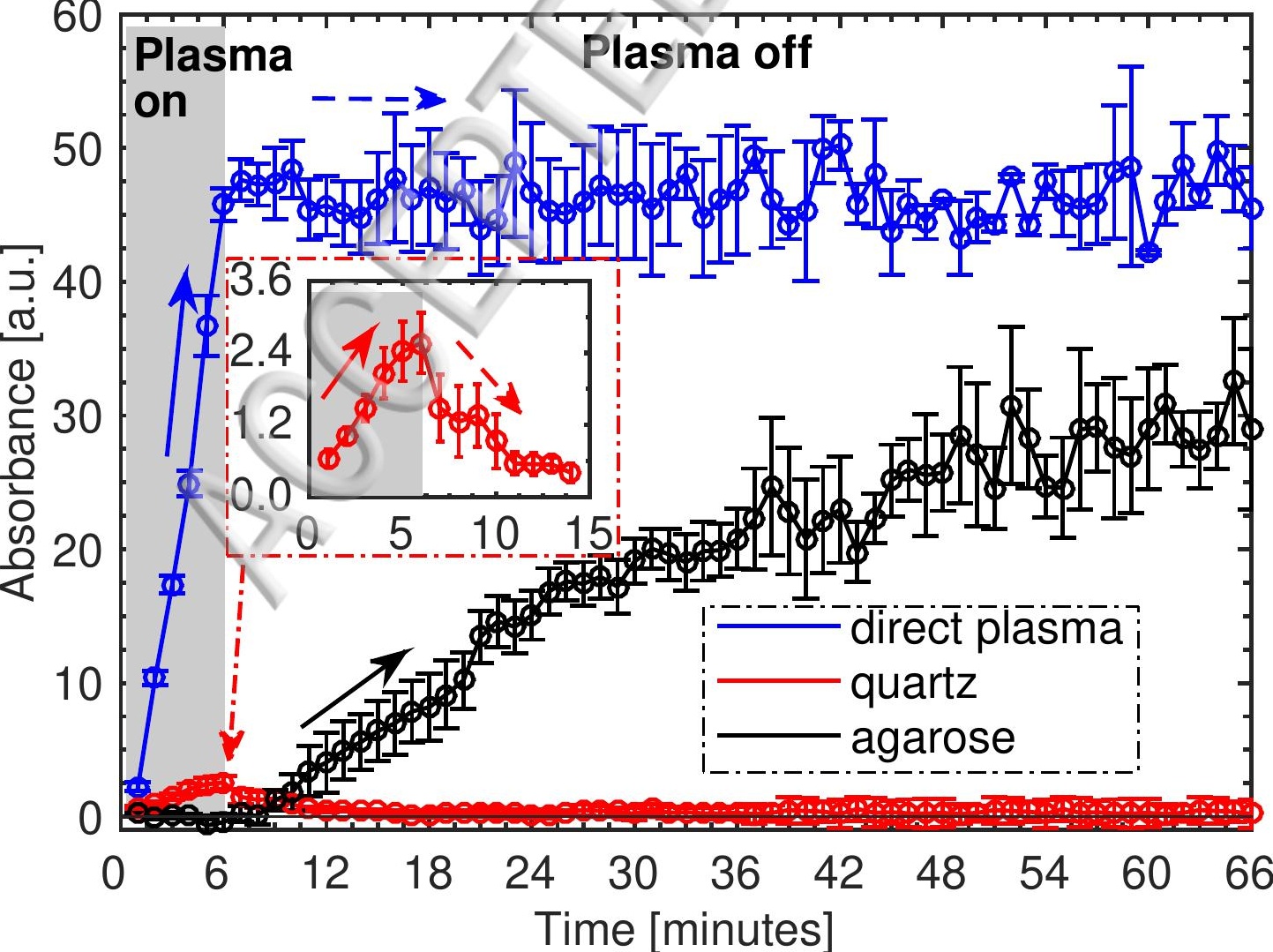




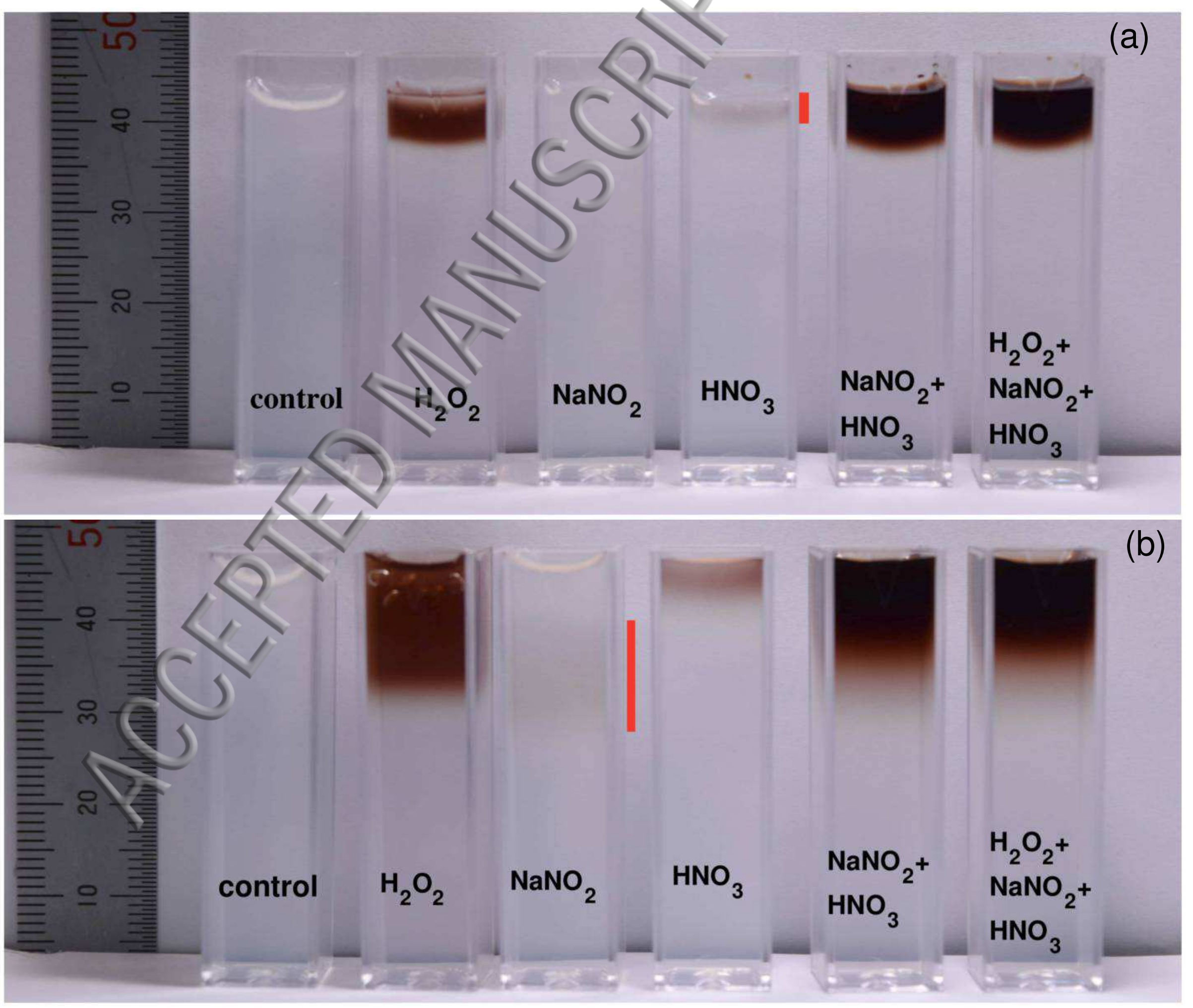

